\title{
Ageing Changes in Human Heart Valves
}

\author{
ARIELA POMERANCE* \\ From the Department of Histopathology, Central Middlesex Hospital, London N.W.10
}

With the increasing number of necropsies on elderly patients, knowledge of ageing changes is becoming important for assessment of pathological findings. Few studies on these changes in human heart valves exist. Gross and Kugel (1931), describing the topographic anatomy and histology, briefly mention findings in the elderly, and more recently McMillan and Lev (1964) studied ageing in 200 human hearts. Their paper dealt mainly with early changes; 44 cases were under 1 year of age, none was over 85 , and only 18 were over 70 . The present communication is concerned with the changes at the other extreme of life, since it is predominantly in elderly patients that difficulties in interpreting the appearances of heart valves are likely to arise.

\section{MatFRIAL AND Methods}

Over a period of 27 months the hearts from all patients aged over 10 years coming to necropsy in this hospital were examined in detail before fixation. Particular attention was paid to the site and degree of valvular thickenings, atheromatous and calcific deposits, scarring and other focal lesions, fusion and fenestration of semilunar valves, and ballooning of atrio-ventricular valves. Valves distorted by acute or chronic endocarditis were excluded from the present study. Atrio-ventricular valve thickening and mitral valve atheromatosis were graded as slight, moderate, or marked, by inspection and palpation. Findings were recorded on a punch card system, together with relevant clinical data. The hearts of all patients under 30 or over 80 , and a representative group from each intermediate hemidecade, were fixed in formol saline, as were all cases with endocardial and valvular abnormalities, however minor. After 5-15 days' fixation, all were re-examined macroscopically, and material was selected for

Received February 2, 1966.

* In receipt of a grant from the North West Metropolitan Regional Hospital Board. microscopy. This included any abnormalities, blocks through each cusp of atrio-ventricular valves and adjacent tissues, and at least one cusp of aortic and pulmonary valves. Routine staining was by hæmatoxylin and eosin, and Weigert's elastic-van Gieson method, with further special stains as required.

\section{RESULTS}

Examinations of 805 suitable hearts were carried out. Ages and sexes are shown in the Table. The terminology proposed by Gross and Kugel (1931) for the various layers (Fig. 1) is used in describing the valvular changes.

Mitral Valve. Changes differed in anterior and posterior cusps and these will, therefore, be considered separately.

(1) Anterior cusp changes: There were two findings, the severity of which increased with age: nodular thickening at the free edge, which, when marked, is generally referred to as senile sclerosis, and lipoid deposition (atheromatosis) nearer the attached part.

(a) Nodular thickening occurred on the atrial surface of the cusp, along the line of contact with the opposing cusp (Fig. 2). It was often slight, particularly in younger people, but present in all adults. Lesions first appeared over the insertions of the chordæ tendineæ, and with increasing severity spread to the areas between the insertions, but remained confined to the zone of apposition. Microscopically, they consist of localized collagenous plaques in the atrialis layer, containing variable amounts of fine elastic fibrils. The normally welldefined elastic laminæ in the deepest part of the atrialis were frequently fragmented or frayed out under these plaques (Fig. 3).

With increasing age the proportion of cases with only slight thickening fell, while those with moderate 
TABLE

AGE AND SEX DISTRJBUTION OF 805 HEARTS EXAMINED

\begin{tabular}{|c|c|c|c|c|c|c|c|c|c|c|}
\hline \multicolumn{2}{|c|}{ Age-group } & Under 15 & $15-24$ & $25-34$ & $35-44$ & $45-54$ & $55-64$ & $65-74$ & $75-84$ & 85 and over \\
\hline $\begin{array}{l}\text { Male subjects } \\
\text { Female subjects }\end{array}$ & 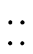 & $\begin{array}{l}1 \\
0\end{array}$ & $\begin{array}{l}3 \\
2\end{array}$ & $\begin{array}{l}8 \\
3\end{array}$ & $\begin{array}{l}13 \\
19\end{array}$ & $\begin{array}{l}38 \\
35\end{array}$ & $\begin{array}{l}81 \\
63\end{array}$ & $\begin{array}{r}100 \\
75\end{array}$ & $\begin{array}{l}111 \\
116\end{array}$ & $\begin{array}{l}59 \\
78\end{array}$ \\
\hline & .. & 1 & 5 & 11 & 32 & 73 & 144 & 175 & 227 & 137 \\
\hline
\end{tabular}
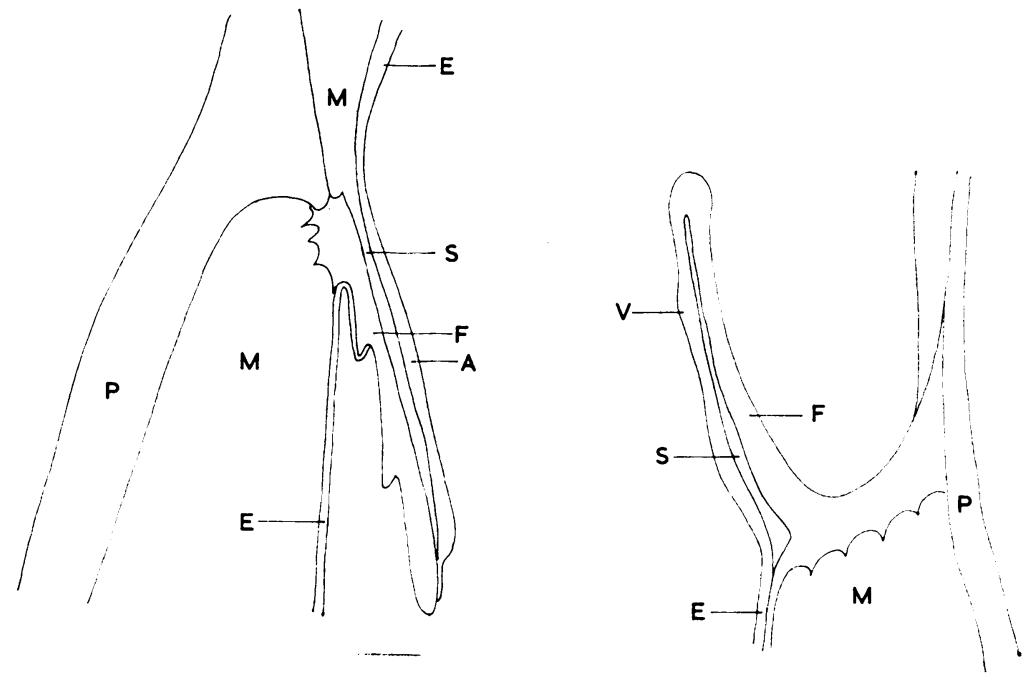

Fig. 1.-Microscopical anatomy of the heart valves (based on Gross and Kugel, 1931). $P=$ pericardium; $\mathbf{M}=$ myocardium; $\mathbf{E}=$ endocardium; $\mathrm{F}=$ valve fibrosa; $\mathrm{S}=$ spongiosa; $\mathrm{A}=$ atrialis (atrio-ventricular valves); $\mathrm{V}=$ ventricularis (semilunar valve).

and marked thickening rose, but almost all this increase occurred in patients under 65; there was very little further change after 65 years. Changes in the degree of nodular thickening with age varied in the two sexes. In the male (Fig. 4) some degree of increase occurred over the whole age range, but was much slower after 65 years. In the female there was no correlation with ageing (Fig. 5); though the highest incidence of marked thickening was in the 65-74 year group this was only slightly more than in the remainder, and there was no difference between patients under 45 years and those over 75 . The most unexpected finding in both sexes was the high proportion with only slight changes even in the oldest group.

(b) Atheromatosis of the anterior cusp of the mitral valves is also considered to be related to age (McManus and Lupton, 1963), and results in this study confirm this view. There was a clear correlation between severity of lipoid deposition, assessed macroscopically, and age (Fig. 6). This was the same in both sexes. In the earliest stages, the atheromatous lesions appear as small white or yellow foci on the ventricular surface of the anterior cusp,

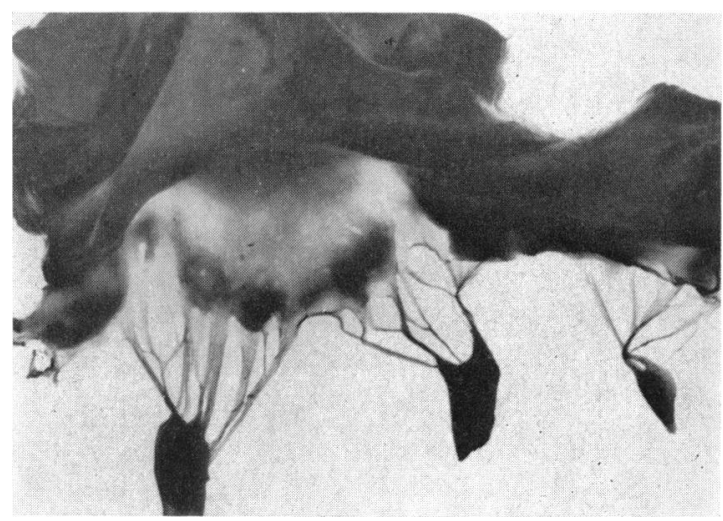

FIG. 2.-Transilluminated anterior cusp of mitral valve from a male subject aged 21 showing localized thickenings over the insertions of the chordæ tendineæ ( $\times 1 \frac{1}{4}$ approx.). 


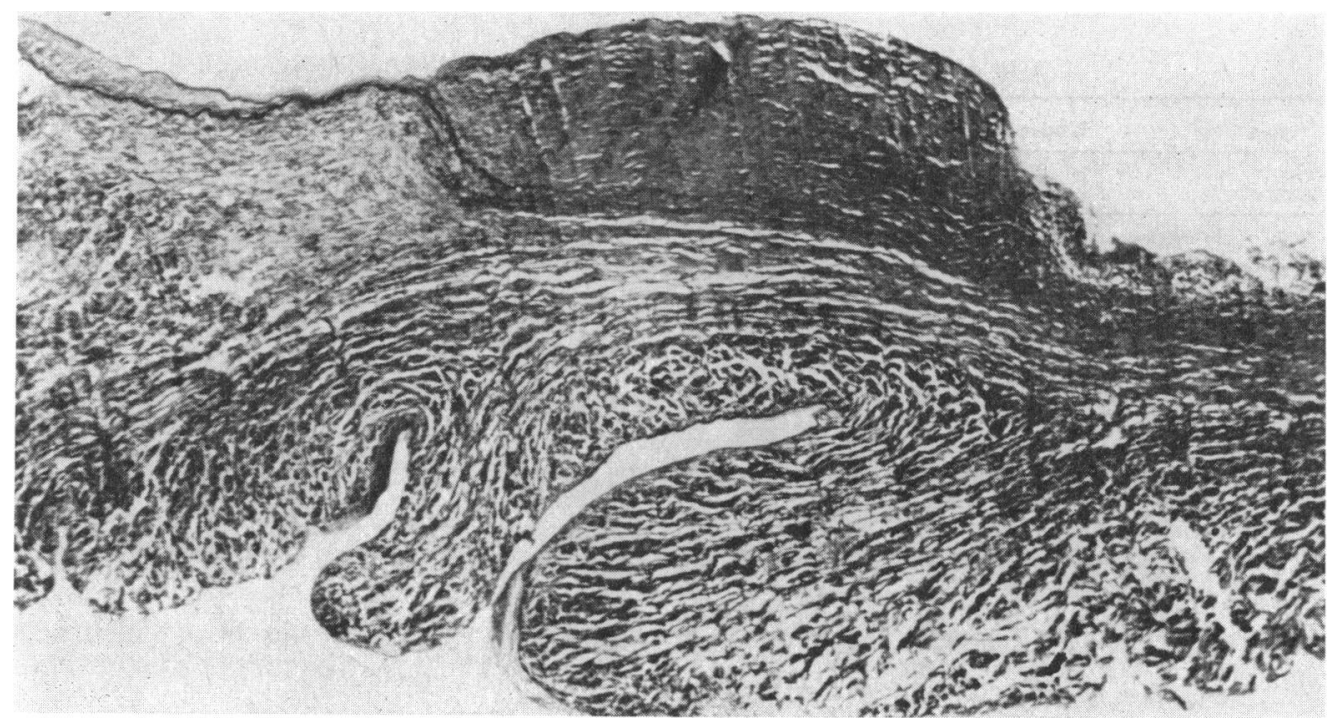

FIG. 3.-Collagenous plaque in mitral atrialis, with frayed and broken elastic lamina in its deepest part. (Weigert's elastic-van Gieson. $\times 40$.)

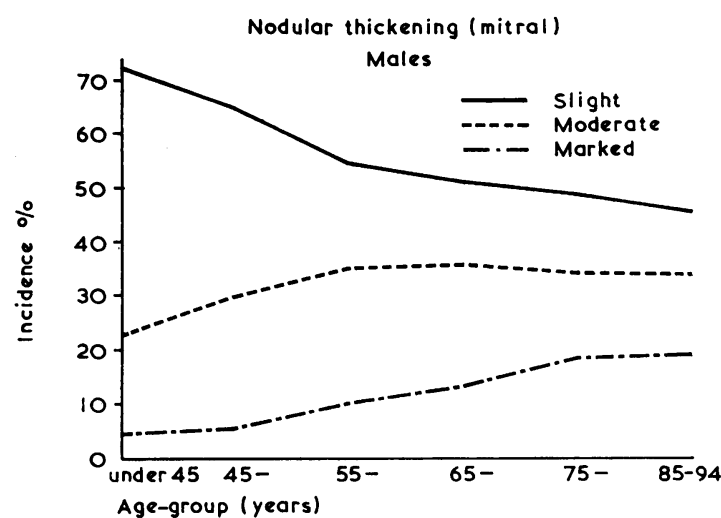

FIG. 4.-Relation of mitral nodular thickening to age in male subjects.

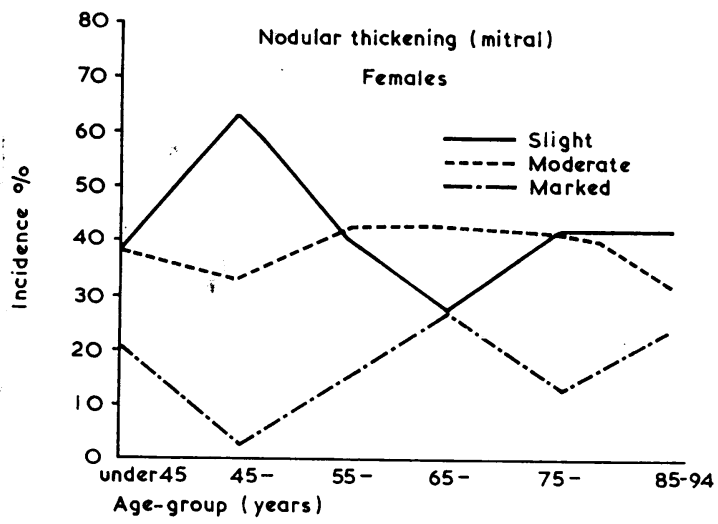

FIG. 5.-Relation of mitral nodular thickening to age in female subjects.

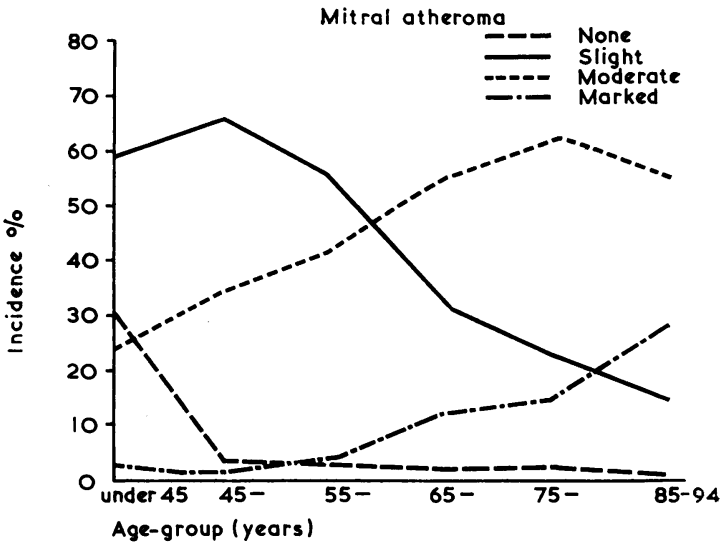

FIG. 6.-Relation of the severity of anterior mitral cusp atheromatosis to age.

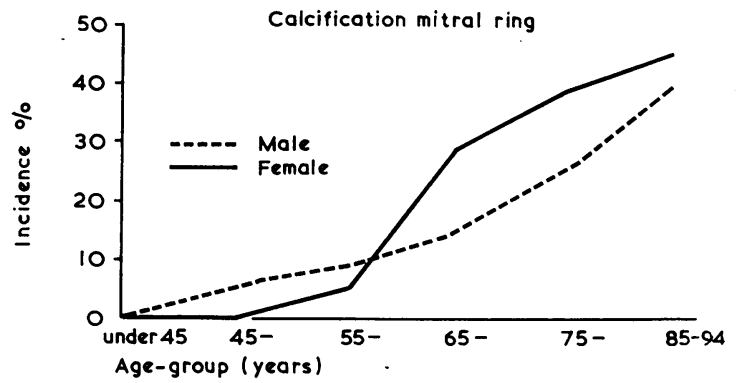

FIG. 7.-Changes in the incidence of mitral ring calcification with age and sex. 
almost always at the lateral margin of the attached edge. With increasing severity lipoid deposition spread distally but rarely reached beyond the zone where the chordæ tendineæ are inserted, though frequently extending into the chordæ themselves.

Complete absence of macroscopic lipoid was common in patients under 45 years, more so in female $(30 \%)$ than in male $(23 \%)$ cases. Slight atheromatosis was the usual finding in those under 65. The proportion with this degree decreased steadily with age, while moderate and later marked changes increased, but the maximum incidence of marked atheromatosis was only 28 per cent.

(2) Posterior cusp changes: In the posterior cusp of the mitral valve four changes occurred with sufficient frequency to warrant study.

(a) The most striking change with age was the rise in incidence of mitral ring calcification. This was never seen under 45 years; there were early changes in two male cases under 55, and in older patients there was a marked rise with ageing. This was greater in the female, so that though mitral ring calcification was initially more common in the male, over the age of 65 years the incidence was considerably higher in women (Fig. 7).

(b) Small puckered scars were seen in about 5 per cent of men over 65 and 3 per cent of women. Microscopically these showed disorganization of the normal layers of the cusp, the atrialis, spongiosa, and fibrosa being fused into a homogeneous area of collagen with irregular elastic fibrils. Small vessels were occasionally seen, but other evidence of previous valvulitis was rarely demonstrable. The lesions were not related to the line of closure of the valve, and though less common in patients under 65 they showed no progressive correlation with age. They have been discussed in a previous study (Pomerance, 1965).

(c) A more constant finding, particularly in the female, was diffuse opacity of the cusp. This was already present in 17 per cent of cases under 45 years, and the incidence increased steadily with age (Fig. 8). It was slightly less common in the male cases, but also increased with age. This appearance was the result of a mild fibro-elastic hyperplasia of the atrialis, similar to, and continuous with, the atrial changes described by McMillan and Lev (1959).

(d) The fourth abnormality sometimes involved the anterior cusp of the valve also, but the most striking changes always appeared in the posterior cusp. This condition has been described in elderly dogs as "billowing sail" distortion (Oka and Angrist, 1961), and in man two cases are recorded as "mucoid degeneration" (Fernex and Fernex, 1958).

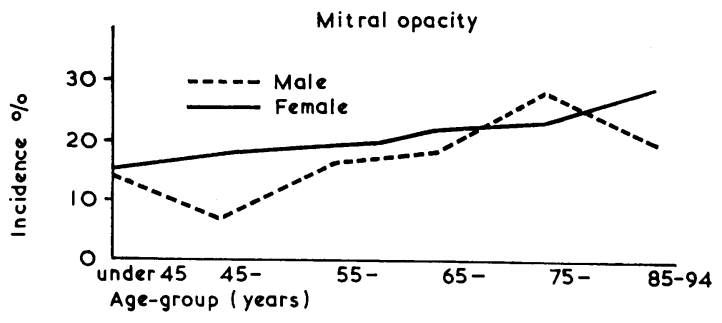

Fig. 8.-Changes in the incidence of opacity of the posterior mitral cusp with age and sex.

The cusps become thickened, opaque, and voluminous, resembling a parachute (Fig. 9). The chordæ tendineæ become attenuated and may rupture. Histologically, there is metachromatic degeneration involving mainly the distal half of the valve fibrosa. The severity of this condition varies from localized areas of ballooning, usually in the centre of the posterior cusp, to gross ectasia, with prolapse of the voluminous cusps into the atrium in systole, resulting in mitral incompetence. Such severe degrees were not common and appeared unrelated to age, but lesser degrees were frequent, and the incidence of these rose with age up to 64 years in the male and 74 years in the female (Fig. 10) with little further change with increasing years.

Aortic Valve. In the few patients under 20 years, the aortic valve cusps were uniformly translucent, thin, and flexible.

(a) Over this age noduli Arantii were present in almost all cases. The non-coronary cusp nodulus was the first to appear, and remained the largest in 60-80 per cent of valves. Like the nodular plaques on the mitral valve, microscopically these consisted of localized fibro-elastic proliferation in the ventricularis, with fragmentation of the underlying elastic laminæ again often visible. In older patients Lambl's excrescences became incorporated (Fig. 11).

(b) Firm ridge-like thickenings at the bases of the aortic cusps also developed early, and did not become more frequent with advancing age (Fig. 12).

(c) In older patients these two findings became obscured by calcification in the valve fibrosa, the incidence of which increased sharply with age. It occurred slightly earlier in males, but the sexes were otherwise similarly affected (Fig. 13).

(d) Fenestration of the cusps adjacent to their commissures was already present in 12 per cent of patients under 45 (Fig. 14) and in the female showed no further change with advancing age. In the male there was a slight rise in the next decade, and no further increase. 


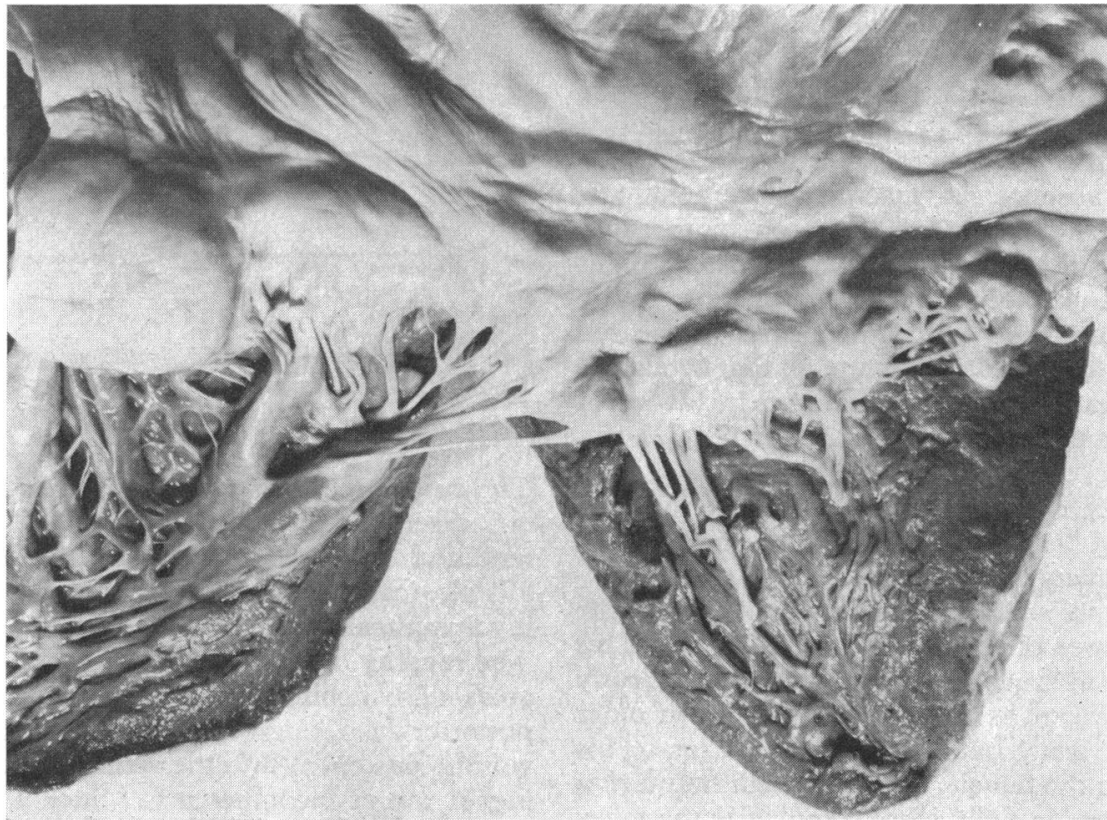

Fig. 9.-Opened left side of heart showing well marked "ballooning" and generalized thickening of the posterior mitral cusp ( $\times 1 \frac{1}{2}$ approx.).

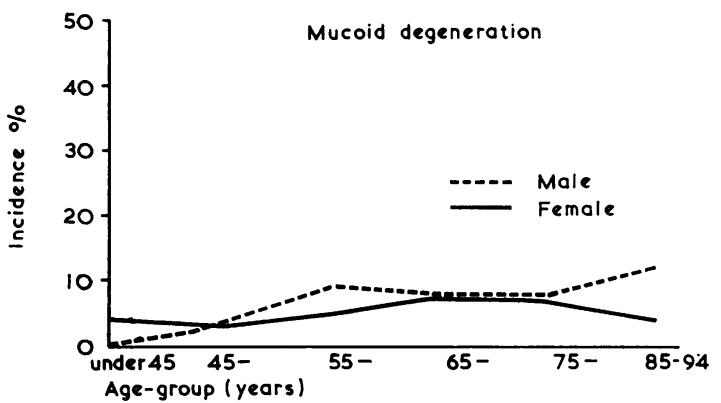

FIG. 10.-Incidence of mucoid degeneration of the mitral valve by age and sex.

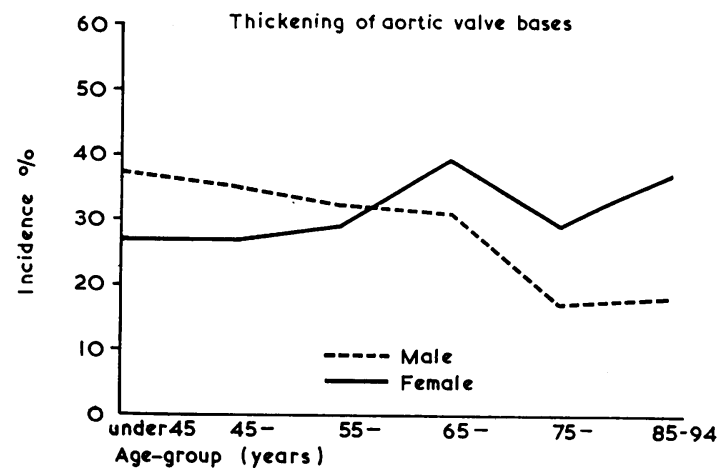

FIG. 12.-Incidence of thickening of aortic valve bases by age and sex.

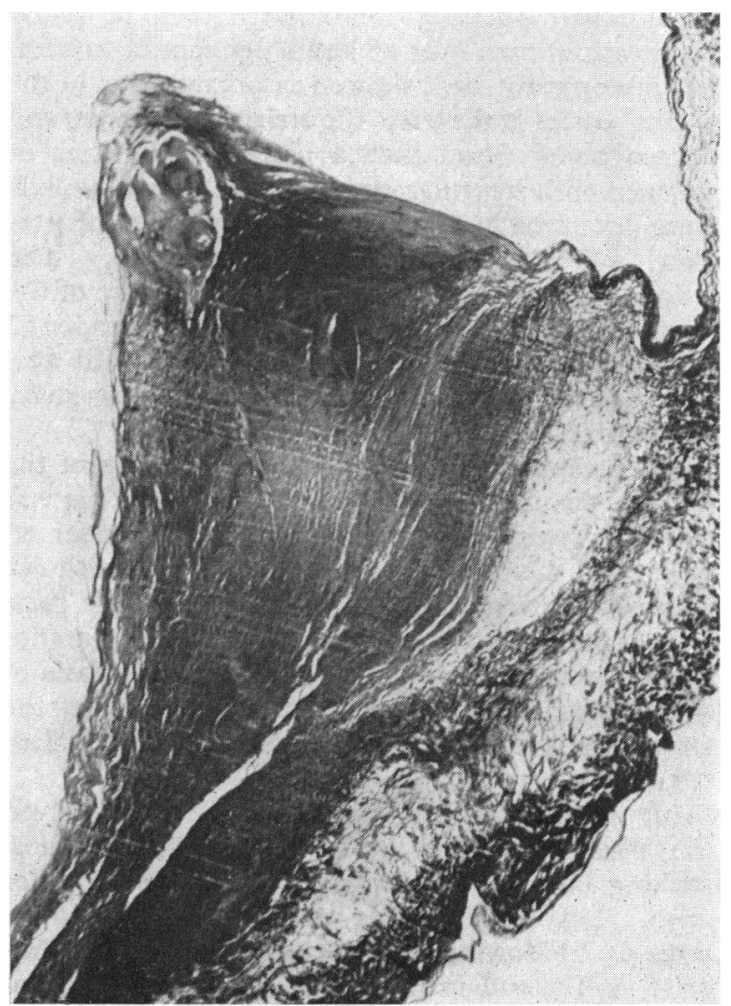

FIG. 11.-Photomicrograph of a nodulus Arantus, showing incorporation of a Lambl's excrescence at its apex. Note fragmented elastic lamina at ventricularis/fibrosa junction. (Weigert's elastic-van Gieson. × 31.) 


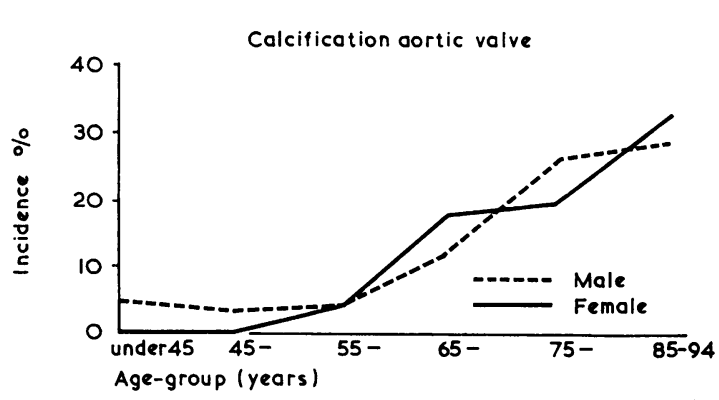

FIG. 13.-Incidence of aortic cusp calcification by age and sex.

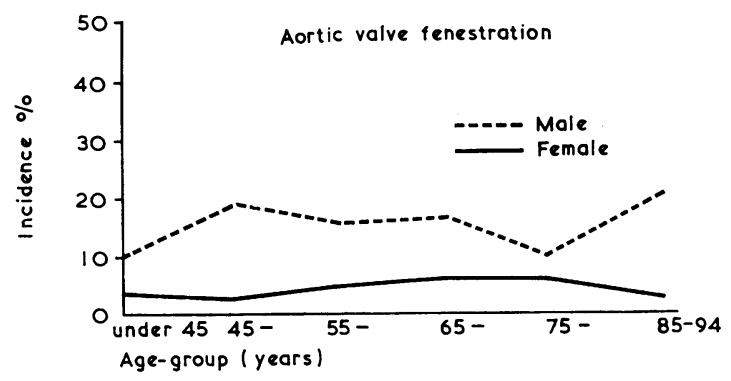

FIG. 14.-Incidence of fenestration of aortic valve by age and sex.

(e) Commissural adhesions and broadening of the commissures were also commoner in the male cases. The incidence of adhesions rose steadily with age (Fig. 15) falling slightly in the oldest group of males, but not in females. Broadening of the commissures was relatively uncommon with a maximum incidence of only 4 per cent in male cases of 75-84 years, and found only in this age-group in female cases $(2 \%)$.

Tricuspid Valve. The only change associated with ageing in the tricuspid valve was a nodular fibro-elastic thickening similar to that found in the anterior cusp of the mitral valve. As in the mitral valve, these changes were found in the longest, most active cusp-the anterior. Unlike the mitral, most patients under 65 years had thin completely translucent cusps, and those with more than a slight degree of thickening were in the minority even in the over 85-year group. The sexes differed slightly in the relation between degrees of thickening and ageing, little further increase in thickening occurring after the 65-74 year group (Fig. 16) in women, while a progressive slight change continued with increasing age in men (Fig. 17).

A curious finding in some of the cases with marked thickening of the anterior cusp was a localized area

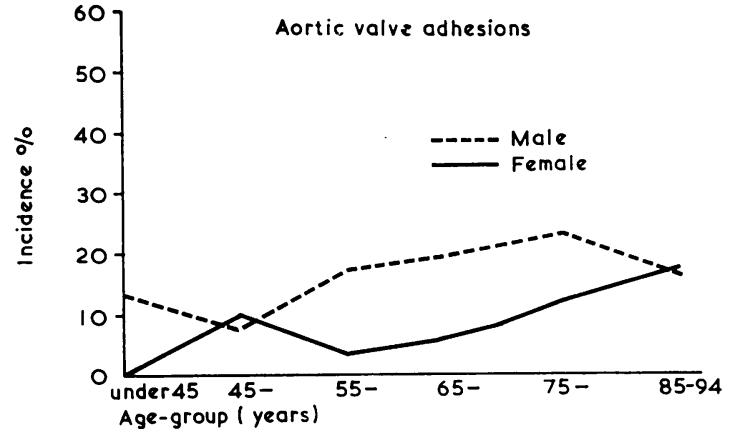

FIG. 15.-Incidence of aortic commissural adhesions by age and sex.

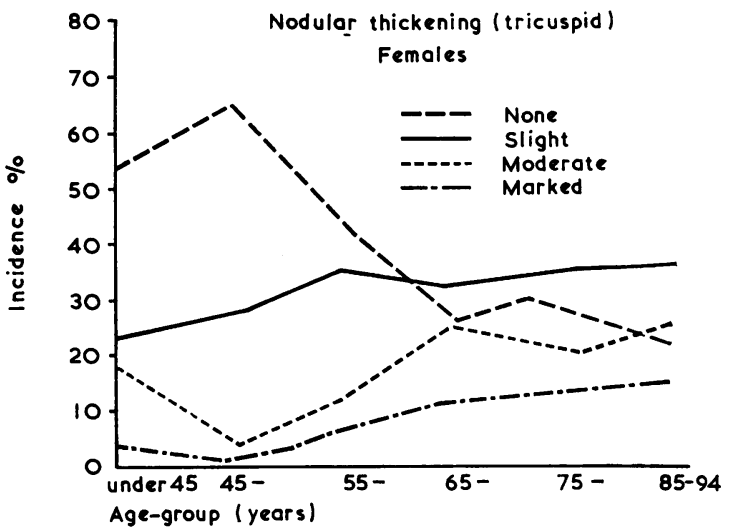

Fig. 16.-Relation of tricuspid nodular thickening to age in female subjects.

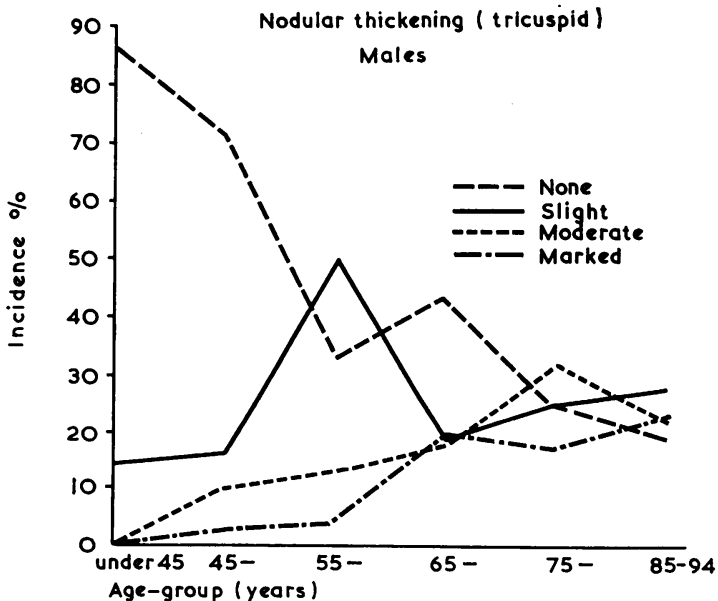

FIG. 17.-Relation of tricuspid nodular thickening to age in male subjects. 


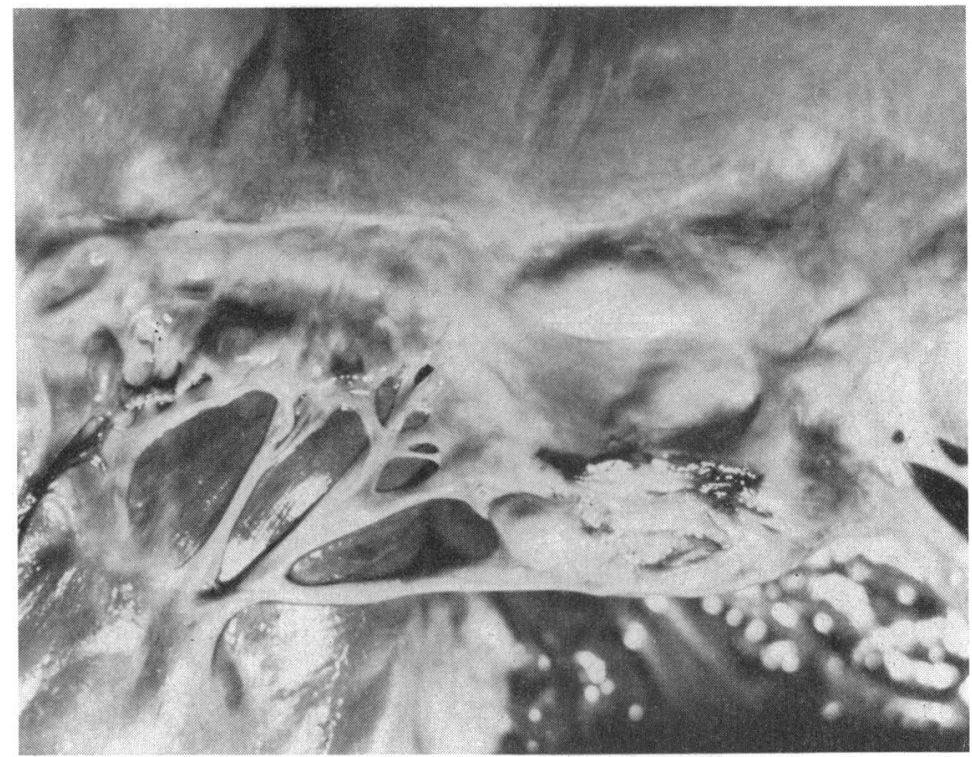

Fig. 18.-Anterior cusp of a tricuspid valve, which is very thickened and shows superficial ulceration. The proximal margin of the ulcer is hæmorrhagic. ( $\times 2$ approx.)

of ulceration in the superficial part of the plaque (Fig. 18). The microscopical features of this lesion were constant and characteristic, with bands of fine fibrillar material staining as elastic fibres at the margins of the ulcerated zone, small amounts of adherent fibrin, and absence of inflammatory reaction. The incidence of these ulcers followed that of marked nodular sclerosis up to the 65-74 year group, but fell with further increasing age to 10 per cent in the male and 5 per cent in the female over 85 years.

Pulmonary Valve. This valve changed very little with age, remaining translucent and pliable even into the tenth decade. The only changes observed were an increasing incidence of nodular thickenings at the centres of the free edges of the

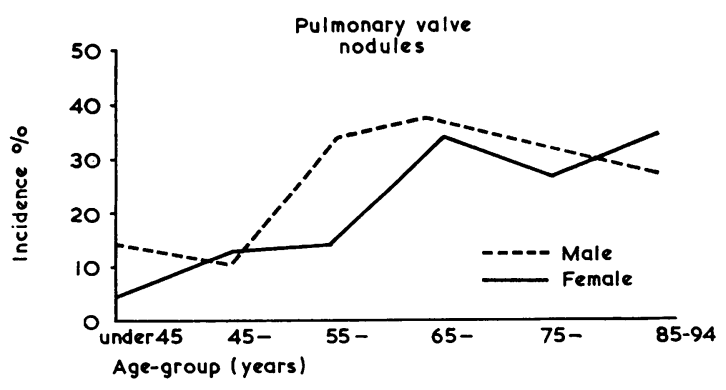

FIG. 19.-Incidence of pulmonary valve noduli Morgani by age and sex. cusps (noduli Morgani). These also consisted of fibro-elastic plaques, and like the histologically similar lesions in other valves, reached their maximum incidence in the 65-74 year group (Fig. 19). Fenestration of the cusps was seen in up to 7 per cent of cases, but though it was slightly more frequent in patients over 65 years there was no progressive change with ageing.

\section{Discussion}

The lack of a standard for normal valve thickening, commented on in Rosenthal and Feigin's (1947) study on mitral valves in older patients, has been rectified by Gavey (1949). His standard for the normal valve in any age-group as "the least degree of change observed in that group" has been used in the present study.

The changes observed fell into three groups-(a) those progressively increasing throughout the age range examined, (b) those whose development was confined to middle age, and (c) those whose incidence did not increase during adult life.

Progressive ageing changes were seen only in the left side of the heart. In the endocardium, fibroelastic hyperplasia of the outflow surfaces was apparent as diffuse white opacity of the posterior mitral cusp, and also resulted in commissural adhesions between aortic cusps. The mitral valve changes were in continuity with histologically similar changes described in the atrial endocardium by Macmillan and Lev (1959) and considered to be 
an irritational hyperplasia stimulated by blood flow. Some degree of hyperplasia was present in all adults. However, this was sufficient to be macroscopically identifiable in only 30 per cent of even the oldest patients, suggesting that factors other than duration of stimulus alone determine the degree of endocardial response to the flow.

In the fibrosa the progressive changes comprised atheromatosis of the anterior mitral cusp and calcification of the aortic valve cusps and mitral valve ring. McManus and Lupton (1963) also found a correlation between mitral atheromatosis and ageing; they considered that the pathogenesis was similar to that of atheroma in other sites and related to blood lipoid levels and hæmodynamic stress. However, their findings of correlations between severity of mitral atheroma and aortic or coronary atheroma and ischæmic heart disease were not confirmed by statistical studies carried out on the present material (Pomerance, 1966a). McMillan and Lev (1964) and Hellwig (1942) agreed on the importance of hæmodynamic factors, but the former implicated the direct effects of high hydrostatic pressures and turbulence on the endocardium, while the latter thought repeated percussive effects caused flocculation of lipoid previously in colloid solution in the valve ground substance. Observations in the present study support the view of McMillan and Lev (1964), since lipoid deposits were limited to sites of highest hydrostatic pressure (i.e. proximal to the chordæ tendineæ insertions) and not found at the zones of valve contact.

Similar hæmodynamic factors appear concerned in aortic cusp calcification. This is preceded by lipoid deposition (Sell and Scully, 1965) similar to mitral atheromatosis; the sexes are also equally involved, and the calcium is deposited in the part of the cusp most affected by valve movements (Hultgren, 1948). The progressive increase in this type of calcification with age is, therefore, also likely to be a result of repeated mechanical stimuli over an increasing period of time.

In calcification of the mitral valve ring, however, other factors must be involved. In contrast to aortic valve calcification, there is a striking sex difference, particularly between 65 and 85 years when macroscopic calcification was seen in 36 per cent of the female compared with 20 per cent of the male cases. The calcium is deposited in a relatively immobile part of the valve, and is not preceded by lipoid similar to the aortic and anterior mitral cusp infiltration. Skop and Souckova (1961) commented on the predisposition of the female to calcification of the cardiac skeleton and Sell and Scully (1965) also noted the sex difference. As women are more commonly affected by senile osteoporosis, Blanken- horn (1964) postulated the existence of a factor affecting body calcium distribution between bone and soft tissue, and suggested this was more active in aged women.

Findings that did not increase in incidence after maturity included the manifestations of cellular ageing already described by McMillan and Lev (1964) and not included in the present study. These authors also considered fenestrations of the aortic valve as developmental, though the incidence increased slightly after maturity. They agreed with Foxe (1929) that hæmodynamic stresses were directly responsible for the fenestrations, but thought these occurred only where fibrous conversion of spongiosa had been delayed.

The incidence of palpable thickening of aortic cusp bases did not change appreciably after maturity and noduli Arantii were already present in all adult aortic valves. The location of the noduli and fragmentation of elastica at their bases indicated that these resulted from forceful impact of the valve at closure. The observation that the non-coronary nodulus was usually the largest was additional confirmation since the entry of blood into the coronary arteries would slightly decrease the pressure on the centre of the lines of closure of both coronary cusps.

The normal slight degree of thickening on the line of apposition of the anterior mitral cusp should also be included in this group, since it was present in all adults. Like the aortic valve endocardial nodules, the location and histological features of the mitral thickenings indicate that they were a response to repeated impact. It seems, therefore, that some degree of damage and endocardial fibrous thickening is an early normal response to the relatively forceful hæmodynamic pressures in the systemic circulation; the lower pressures in the lesser circulation are insufficient to produce similar changes in the right heart valves. Although slight thickening of the anterior mitral cusp is accepted as normal (Rosenthal and Feigin, 1947; Gavey, 1949), greater degrees of atrio-ventricular thickening are not. Together with pulmonary noduli Morgani and mucoid degeneration of mitral valves, they form the intermediate group of changes whose development was largely limited to the middle age-groups. The pathogenesis of excessive thickening is described more fully in another communication (Pomerance, 1966b). Briefly, no support was found for the views of Robbins (1962), Rezek and Millard (1963), and Angrist (1964) that atherosclerosis or endocarditis played a part. After standardization for age and sex there was no significant correlation with systemic hypertension or cardiac hypertrophy, but a highly significant correlation between the presence of chronic pulmonary disease and the degree of both 
mitral and tricuspid thickening. Similar valve lesions can be induced experimentally by hypoxia (Dalton et al., 1945; Highman and Altland, 1949), and this may, therefore, also influence the degree of endothelial proliferation in human valves.

The rtiology of mucoid degeneration of valve fibrosa is obscure. Although it has been described as an ageing change (Oka and Angrist, 1961; Angrist, 1964) and until recently has been recorded in only 3 elderly patients (Fernex and Fernex, 1958; Caird, 1963), cases in younger people are now being recognized (Hudson, 1965; Linhart and Taylor, 1965), and Karsner's (1941) view that this is a disease process seems more appropriate.

In conclusion, it is clear that hæmodynamic factors are responsible for most of the ageing changes in human heart valves. Forceful contact causes the fibrous plaques seen as thickenings on the zones of apposition of the valves of the left side of the heart; these develop early and are normally already present in all adults. The flow of blood over mitral and aortic cusps stimulates hyperplasia which results in mitral opacity and aortic commissural adhesions. The hydrostatic pressures causing valve closure determine the fibrosa changes; these progress continuously with ageing. Conditions which increase in incidence or severity during middle age but do not progress further in old age are not considered true ageing changes but a manifestation of other pathological processes.

\section{SUMMARY}

Ageing changes in the heart valves of 805 patients aged 10-96 years have been studied.

There was considerable variation between hearts in the same age-groups, but noduli Arantii and slight anterior mitral nodularity were already present in all adult hearts. The histology and location of these endocardial thickenings indicated that they were a reaction to local injury produced by forceful contact between the cusps. At least slight mitral atheromatosis was present in 99 per cent of all patients over 55. As these were frequently the only findings, even in the tenth decade, they form the normal appearance of the valves in old age. Further changes were, however, common. Those increasing progressively throughout the age range studied were found only in the left side of the heart. In the fibrosa they consisted of mitral atheromatosis, aortic valve calcification preceded by similar atheromatosis, and mitral ring calcification. The two former increased steadily with age, were unrelated to sex, and were thought to result from the hæmodynamic forces causing valve closure. The latter increased exponentially with age, was commoner in women, and hæmodynamic factors did not appear important in pathogenesis. The incidence of diffuse opacity of the posterior mitral cusp and aortic commissural adhesions also rose steadily with age. Both appearances resulted from diffuse fibroelastic hyperplasia of the valve endocardium. This is also thought to be a hæmodynamically stimulated reaction, in response to the less forceful blood flow over opening valves.

Changes that progress only during middle age, with no further increase after the 65-74 year group, were not considered to be directly related to ageing. They included excessive nodular thickening ("senile" nodular sclerosis) of atrio-ventricular valves, and mucoid degeneration of mitral valve. The pathogenesis of nodular sclerosis is briefly discussed and its probable relation to chronic pulmonary disease suggested. The ætiology of mucoid degeneration is unknown. The low incidence in the elderly indicates that, in man, it is not an involutional process and the slight increase with ageing is merely an expression of the increasing incidence of disease processes generally.

I should like to thank Dr. R. A. B. Drury for his continued support and provision of laboratory facilities, the staff of the Histopathology Department for the considerable amount of extra technical work involved, and Mr. A. Booker and Dr. D. Trevan for the photography.

\section{REFERENCES}

Angrist, A. (1964). Aging heart valves and a unitary pathological hypothesis for sclerosis. F. Geront., 19, 135.

Blankenhorn, D. H. (1964). The relation of age and sex to diffuse aortic calcification in man. F. Geront., 19, 72.

Caird, F. I. (1963). Heart disease in old age. Postgrad. med. F., 39, 408.

Dalton, A. J., Jones, B. F., Peters, V. B., and Mitchell, E. R. (1945). Organ changes in rats exposed repeatedly to lowered oxygen tension with reduced barometric pressure. F. nat. Cancer Inst., 6, 161.

Fernex, M., and Fernex, C. (1958). La dégenerescence mucoïde des valvules mitrales, ses repercussions fonctionnelles. Helv. med. Acta, 25, 694.

Foxe, A. N. (1929). Fenestrations of the semilunar valves. Amer. F. Path., 5, 179.

Gavey, C. J. (1949). The cardiology of old age. Lancet, 2, 725.

Gross, L., and Kugel, M. A. (1931). Topographic anatomy and histology of the valves in the human heart. Amer. F. Path., 7, 445.

Hellwig, C. A. (1942). Atheromatosis of the mitral valve. Amer. Heart f., 24, 41.

Highman, B., and Altland, P. D. (1949). Acclimatization response and pathologic changes in rats at an altitude of 25,000 feet. Arch. Path., 48, 503.

Hudson, R. (1965). Cardiovascular Pathology, p. 1966. Arnold, London.

Hultgren, H. N. (1948). Calcific disease of the aortic valve. Arch. Path., 45, 694.

Karsner, H. T. (1941). Involutionary changes in the cardiovascular system. In Univ. Pennsylv. Bicentennial Conf., pp. 17-26. University of Pennsylvania Press, Philadelphia. 
Linhart, J. W., and Taylor W. J. (1965). Late apical systolic murmur: clinical, hemodynamic, and angiographic data in seven patients. Circulation, 31 and 32, Suppl. 2, p. 139.

McManus, J. F. A., and Lupton, C. H. (1963). Lipid deposits in the aortic cusp of the mitral valve. Arch. Path., 75, 674.

McMillan, J. B., and Lev, M. (1959). The aging heart, I. Endocardium. F. Geront., 14, 268.

$\longrightarrow$, and - (1964). The aging heart, II. The valves. f. Geront., 19, 1.

Oka, M., and Angrist, A. (1961). Fibrous thickening with billowing sail distortion of the aging heart valve. Proc. N.Y. St. Ass. publ. hlth Labs., 46, 21.

Pomerance, A. (1965). Pathology of the heart with and without cardiac failure in the aged. Brit. Heart f., 27, 697. (1966a) Studies on atheromatosis of the mitral valve. $\mathcal{F}$. Atheroscler Res. In the press.

- (1966b) Pathogenesis of "senile" nodular sclerosis of atrio-ventricular valves. Brit. Heart. F., 28, 815.

Rezek, P. R., and Millard, M. (1963). Autopsy Pathology, p. 256. C. C. Thomas, Springfield, Illinois.

Robbins, S. L. (1962). Textbook of Pathology with Clinical Applications, 2nd ed., p. 397. W. B. Saunders, Philadelphia and London.

Rosenthal, J., and Feigin, I. (1947). Pathology of the mitral valve in the older age groups. Amer. Heart f., 33, 346.

Sell, S., and Scully, R. E. (1965). Aging changes in the aortic and mitral valve. Amer. F. Path., 46, 345.

Skop, V., and Souckova, E. (1961). Calcification of the heart skeleton and valves [translated abstract]. Excerpta med. (Amst.), Sect. XVIII, 5, 211.

\section{The following papers will appear in an early issue of this fournal}

Ballistocardiography

Pulmonary Artery Banding for Ventricular Septal Defect

The Eight-hour Electrocardiogram: Technique and Clinical Application

Left Atrial Impulse Formation in Atrial Flutter

Computers in Cardiovascular Investigation

Lung Function in Patients with Left-to-right Shunts

Assessment of Site and Severity in Congenital Aortic Stenosis

Modification of Cardiovascular Responses by Propranolol

Catheterization of the Left Atrium by Ross Needle and Seldinger Wire Techniques

Cardiomyopathy and Pregnancy

Geographical Aspects of Acute Myocardial Infarction in India with Special Reference to Patterns of Diet and Eating

Conversion of Atrial Fibrillation and Flutter by Propranolol

Incidence of Atherosclerotic Lesions at Madras, South India

Chronic Hæmolysis Occurring in Patients Following Cardiac Surgery
D. C. Deuchar

R. G. Grainger, R. E. Nagle, C. Pawidapha, D. S. Robertson, D. G. Taylor, J. A. Thornton, D. Verel, and R. B. Zachary

C. E. Aranaga, M. M. Mower, W. S. Staewen, and B. Tabatznik

M. Mirowski and W. J. Alkan

S. H. Taylor, H. R. Macdonald, M. C. Robinson, and R. P. Sapru

Hywel Davies and Nikos Gazetopoulos

Celia M. Oakley and K. A. Hallidie-Smith

John H. K. Vogel and S. Gilbert Blount, Jr.

D. Verel

A. K. Brown, N. Doukas, W. D. Riding, and E. Wyn Jones

S. L. Malhotra

Steven Wolfson, Michael V. Herman, Jay $M$. Sullivan, and Richard Gorlin

R. Subramaniam and Abraham C. Kulangara

R. Edward Bell, Stephen Petuoglu, and R. S. Fraser 